\title{
Loyd V. Allen (Editor-in-chief): Remington, the science and practice of pharmacy
}

\author{
22nd Edition, The pharmaceutical Press, London, Philadephia, 2013, ISBN 978085711 \\ 062 6. Official price: $€ 148.00 / £ 120.00 /$ US $\$ 185.00$ (it can be wise to shop around)
}

\author{
J. W. F. van Mil
}

Received: 24 November 2012/ Accepted: 27 November 2012/Published online: 19 December 2012

(C) Springer Science+Business Media Dordrecht 2012

Over 4 kilo's of pharmacy information on more than 2,700 pages in two volumes. A new edition of the Remington appears every 5-6 years, and it is becoming heavier and heavier. For many English speaking pharmacists and pharmacy students it is the reference. The book describes the science and practice of pharmacy, where the practice is now concentrated in the second volume.

The book was first published in 1886 by Joseph P. Remington, but from the edition of 1948 onwards, the Philadelphia College of Pharmacy was responsible for it. The newest version is published in close cooperation with the London-UK based Pharmaceutical Press, which also publishes the Martindale. And the two reference books started working together in this edition, in order to make the Remington more international.

In the first volume, the science of Pharmacy is described in 6 sections: Introduction (with information about the scope and evaluation of pharmacy and a chapter on information resources); Pharmaceutical Chemistry; Pharmaceutical analysis and Quality control; Pharmaceutics; Pharmaceutical Dosage Forms: Manufacturing and Compounding; Pharmacokinetics and Pharmacodynamics. Every section has a number of, sometimes highly specialised, chapters written by experts, and properly referenced. References come almost exclusively from English-language journals and books from the USA and UK. This may limit the comprehensiveness.

The section with pharmaceutical and medicinal monographs now also incorporates the key information from the 37th Martindale. It is unclear why both the Remington and the Martindale should contain similar information. Using

J. W. F. van Mil (ه)

Margrietlaan 1, 9471 CT Zuidlaren, The Netherlands

e-mail: jwfvmil@planet.nl the Remington would be much easier without the 600 pages of monographs, and almost every pharmacist does have the Martindale somewhere. Actually, monographs should no longer be printed, but presented on the web, to be able to update the information instantly. Luckily, like the Martindale, the Remington has an on-line version, and when you buy the book you also get free access to the online data.

The second volume of the Remington, on the practice of pharmacy, does not really have an international scope. This becomes especially clear in a number of chapters, of which Chapter 91, about 'Laws governing pharmacy', can be called the most striking example. This chapter is about the USA only, and even lacks every reference to the existence of other pharmacy systems in this world. Looking at the extensive reference lists of each chapter, one can also see that the chapters in this volume are almost fully based on American literature. Although the second volume can be of some use to, for instance, European or Asian pharmacists, for them it cannot fulfil the claim of the Editor-in-Chief that the Remington is the definite reference on all aspects of the science and practice of pharmacy. In the big world, it is not.

\section{Conclusion}

The Remington offers a wealth of information on pharmacy practice and pharmaceutical sciences. For American pharmacists it is a true and up-to-date professional reference book; Pharmacists in the rest of the world may certainly use it as a source of information for a number of aspects of the profession. Since Martindale still is the most complete drug reference book, monographs can really be deleted from the Remington forever. That would make the Remington much more handy than it currently is. 